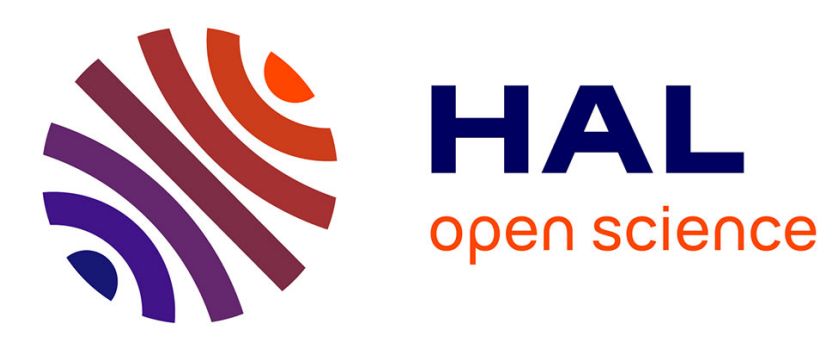

\title{
Electro-optic nonlinear phase dynamics, chaos generation, and cancellation
}

\author{
R. Lavrov, M. Peil, M. Jacquot, L. Larger, Y.K. Chembo
}

\section{To cite this version:}

R. Lavrov, M. Peil, M. Jacquot, L. Larger, Y.K. Chembo. Electro-optic nonlinear phase dynamics, chaos generation, and cancellation. CLEO/Europe-IQEC 2009, Jun 2009, Munich, Germany. 10.1109/CLEOE-EQEC.2009.5196246 . hal-00472358

\section{HAL Id: hal-00472358 https://hal.science/hal-00472358}

Submitted on 12 Apr 2021

HAL is a multi-disciplinary open access archive for the deposit and dissemination of scientific research documents, whether they are published or not. The documents may come from teaching and research institutions in France or abroad, or from public or private research centers.
L'archive ouverte pluridisciplinaire HAL, est destinée au dépôt et à la diffusion de documents scientifiques de niveau recherche, publiés ou non, émanant des établissements d'enseignement et de recherche français ou étrangers, des laboratoires publics ou privés. 


\title{
Electro-optic nonlinear phase dynamics, chaos generation, and cancellation
}

\author{
R. Lavrov, M. Peil, M. Jacquot, L. Larger, Y.K. Chembo
}

University of Franche-Comté, FEMTO-ST Institute, UMR CNRS 6174, 16 route de Gray, F-25030 Besançon cedex, France

Optical chaos communications met intensive research efforts during the last 10 years [1,2], resulting in 2004 in a field experiment in the metropolitan optical network of Athens [3]. Current efforts are now concentrating on device oriented architectures, in order to improve reliability, efficiency, and security. Among the few competitive approaches developed in the literature, the electro-optic one showed first its strong potential in terms of bit rate and decoding quality [4]. However, it was suffering from a few drawbacks in terms of technological complexity, due to the intensity superposition condition required by the mixing between the binary intensity message and the chaotic optical intensity carrier.

Recently, our group developed a new chaos generator, operating with the dynamical variable optical phase, and offering attractive features to answer to most of the open problems left by the previous electro-optic intensity chaos setup: the mixing between the message and the chaos can be easily obtained via two cascaded electrooptic phase modulators, and a custom device performed by a multiple wave passive imbalanced interferometer. The latter could represent a physical hardware key, which can be technologically defined among many different possibilities.
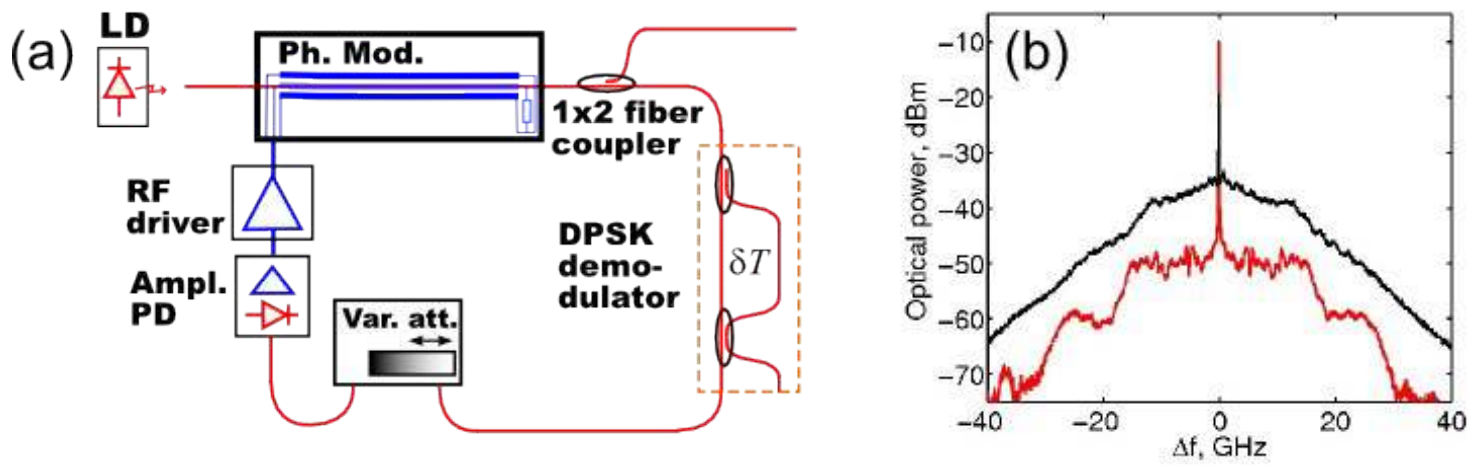

Fig. 1 Generation and cancellation of optical pase chaos: (a) the nonlinear delay electro-optic phase dynamical system, (b): optical spectra of the chaotic phase modulation (black), and chaos cancellation (red).

The setup performing a chaotic phase modulation of the optical carrier is represented in Fig.1(a). It consists of a broadband telecom electro-optic phase modulator, a delay line of a given length (a few $\mathrm{cm}$ to a few $\mathrm{km}$ ), nonlinear phase-to-intensity converter made of a multiple wave imbalanced interferometer, which imbalanced paths need to be greater than the characteristic time of the phase modulation. A photodiode and an rf amplifier allow to close the oscillation loop, thus performing a nonlinear multiple delay (both large and short) differential dynamics. Such dynamics were shown to exhibit complex chaotic solutions, when the feedback gain is adjusted above an easily achievable threshold.

We will report on the first experimental investigations of the dynamical behavior exhibited by such a nonlinear delay optical phase dynamics, together with the derivation of a model. The latter model allowed for numerical simulations, which solutions closely agree qualitatively and quantitively with the experimentally oberved ones.

In the context of optical chaos communications, we will also report on the first experimental demonstration of broadband $(>10 \mathrm{GHz})$ and high quality chaos cancellation through a uni-directional emitter / receiver coupling (synchronization error lower than $-10 \mathrm{~dB}$ as depicted in Fig.1(b) over the full $10 \mathrm{GHz}$ bandwidth). We will also show how fast DPSK messages might be encoded and decoded all optically, thanks to the advantageous features of the phase chaos modulation principles.

\section{References}

[1] J.P. Goedgebuer, L. Larger, H. Porte, "Optical cryptosystem based on synchronization of hyperchaos generated by a delayed feedback tunable laserdiode", Phys. Rev. Lett., Vol.80, No.10, pp. 2249-2252 (1998).

[2] G. Van Wiggeren, R. Roy, "Communicating with chaotic lasers", Science, Vol.279, No.3, pp.1198-1200 (1998).

[3] A. Argyris et al., "Chaos-based communications at high bit rates using commercial fiber-optic links", Nature, Vol. 438, pp.343-346 (2005).

[4] N. Gastaud et al., "Electro-optic Chaos for Encrypted Multi-Gb/s Optical Transmissions", Electron. Lett. Vol.40, No14, pp.898-899, (2004). 